\title{
AVALIAÇÃO DO PROJETO ESPLANADA SUSTENTÁVEL: UM ESTUDO NO INSTITUTO DE PESQUISA ECONÔMICA APLICADA (IPEA)
}

EVALUATION OF THE SUSTAINABLE ESPLANADA PROJECT: A STUDY AT THE INSTITUTE OF APPLIED ECONOMIC RESEARCH (IPEA)

HUGO RAFAEL PEREIRA

Universidade do Estado do Rio de Janeiro

CÁTIA DE ASSIS SILVA DAS CHAGAS

Universidade do Estado do Rio de Janeiro

GUILHERME TEIXEIRA PORTUGAL

Universidade do Estado do Rio de Janeiro

WALDIR JORGE LADEIRA SANTOS

Universidade do Estado do Rio de Janeiro

Recebido em 01/11/18

Avaliado pelo sistema double blind review e solicitado revisões em 08/11/18

Aceito para publicação pelo Editor Chefe Dr. Leonardo José Seixas Pinto em 15/11/18 e publicado em 28/12/18

\section{RESUMO}

$\mathrm{Na}$ busca do controle e eficiência dos gastos, o governo federal instituiu o Projeto Esplanada Sustentável (PES) como ação de controle e eficiência dos recursos públicos e como medida de sustentabilidade socioambiental. O presente estudo tem como objetivo avaliar as práticas sustentáveis de gestão e os objetivos previstos no PES que estão em operação no âmbito do Instituto de Pesquisa Econômica Aplicada (IPEA). Dessa forma, por sua natureza, a pesquisa é definida como exploratória, de abordagem qualitativa e com aplicação de estudo de caso sendo realizada junto ao IPEA. A coleta de dados foi realizada através de documentação direta e indireta, entrevistas e questionários. Os resultados apresentam a análise dos objetivos previstos no PES, onde observou-se importantes contribuições às práticas sustentáveis adotadas pelo IPEA. Dessa forma, dos 7 objetivos do programa, 2 foram atingidos de forma plena, 4 atingidos de forma parcial e um não foi atingido em nenhum grau.

Palavras-Chave: Projeto Esplanada Sustentável; Sustentabilidade socioambiental; Recursos públicos.

\section{ABSTRACT}

In the pursuit of control and efficiency of expenditures, the federal government instituted the Sustainable Esplanade Project (PES) as an action for control and efficiency of public resources and as a measure of socio-environmental sustainability. The objective of this study is to evaluate the sustainable management practices and objectives set forth in the PES that are in operation within the scope of the Institute of Applied Economic Research (IPEA). Thus, by its nature, the research is defined as exploratory, with a qualitative approach and with application of a case study. The research was conducted at the Institute of Applied Economic Research (IPEA). Data collection was done through direct and indirect documentation, interviews and questionnaires. The results of this research present the analysis of the objectives set forth in the PES. Significant contributions to the sustainable practices adopted by IPEA were observed. Thus, of the 7 program objectives, 2 were fully achieved, 4 were partially achieved and one was not reached in any degree.

Palavras-Chave: Sustainable Esplanade Project; Socio-environmental sustainability; Public resources. 


\section{INTRODUÇÃO}

As reformas administrativas modificaram a forma de gestão e controle das organizações, proporcionando uma administração com mais cidadania e democracia. Com o passar dos anos, a eficiência do gasto público é um assunto que vem ganhando destaque no âmbito da Administração Pública, sendo bastante discutida ao longo das últimas décadas.

Diante disso, na busca do controle e eficiência dos gastos, o Governo Federal instituiu, em 2012, o Projeto Esplanada Sustentável (PES), a fim de melhorar a gestão dos recursos públicos e a cultura organizacional nos órgãos. $\mathrm{O}$ respectivo projeto apresenta determinados objetivos, metas e benefícios para o combate ao desperdício de recursos (MPOG, 2012).

Iniciado por órgãos públicos em Brasília, o PES teve sua expansão para todo o Poder Executivo Federal do país (VASCONCELOS; NOGUEIRA, 2014). Considerado um projeto de Política Pública, Figueiredo e Figueiredo (1986, p. 109) apresentam dois propósitos para este tipo de projeto: "gerar um produto físico, tangível e mensurável; e gerar um impacto, que, tanto pode ser físico, tangível e mensurável, quanto subjetivo, alterando atitudes, comportamentos e/ou opiniões".

Com base no exposto, o estudo pretende responder o seguinte problema de pesquisa: $\mathrm{O}$ Projeto Esplanada Sustentável está contribuindo para mudanças nas práticas sustentáveis de gestão? Nesta perspectiva, o estudo tem como objetivo avaliar as práticas sustentáveis de gestão e os objetivos previstos no PES que estão em operação no âmbito do Instituto de Pesquisa Econômica Aplicada (IPEA).

Neste contexto, a pesquisa realizou um estudo no Instituto de Pesquisa Econômica Aplicada (IPEA), localizado no município do Rio de Janeiro/RJ e com sede em Brasília/DF. O IPEA foi a primeira fundação federal a formalizar sua participação voluntária no PES, com a assinatura do termo de adesão em novembro de 2012 (IPEA, 2018). Sendo assim, os resultados encontrados nesta pesquisa limitam-se ao IPEA, instituição da Administração Pública analisada, não sendo possível generalizar os achados deste estudo para outras instituições.

Nota-se que o estudo sobre avaliação do PES se justifica, pois permite diagnosticar o processo de planejamento e controle de recursos públicos, bem como a gestão ambiental e social existente na Administração Pública. Além disso, o estudo contribui para o aperfeiçoamento da gestão pública por meio da análise do PES, observando suas contribuições, seus objetivos e principais fragilidades no que se refere à sua implementação, monitoramento, em especial, àquelas afetas à efetividade operacional.

O estudo está estruturado em cinco seções. A primeira seção, destinada à introdução, contextualiza o estudo, apresenta o problema da pesquisa, o objetivo e justificativa. Na segunda seção, descreve-se a fundamentação teórica. A terceira seção está dedicada aos procedimentos metodológicos. Na quarta seção, apresenta-se os resultados da pesquisa. Na quinta seção, final, são efetuadas as conclusões do estudo.

\section{FUNDAMENTAÇÃO TEÓRICA}

Para alcançar o objetivo proposto pela pesquisa, esta seção apresenta os pilares teóricos deste estudo em quatro subseções. A primeira subseção relaciona os estudos sobre o controle e eficiência na Administração Pública A segunda subseção apresenta o Projeto Esplanada Sustentável (PES). Na terceira subseção, final, contém as formas de avaliação de projetos.

\subsection{Controle e Eficiência na Administração Pública}

O controle é necessário para o cumprimento de metas em uma gestão pública. Segundo Grateron (1999, p. 7), o controle é "[...] uma ação preventiva e corretiva contida em cada uma das fases do processo administrativo de qualquer organização [...]". O autor complementa que o controle exercido por um órgão público consiste no "[...] acompanhamento, observação, fiscalização e exame da gestão pública, com a finalidade de proteger o patrimônio e promover a maior eficácia, eficiência e efetividade nos serviços prestados, corrigindo as falhas e punindo infratores" (AFASANIEV, 1978, apud GRATERON, 1999, p. 7) 
Com relação à eficiência, Cardoso (2003, apud BAPTISLELLI, 2009) destaca que a eficiência é uma ação adequada para maximizar os recursos disponíveis. No mesmo sentido, Malena et al. (2013, p. 4) destacam que os benefícios da eficiência, sob a ótica do gasto, “[...] se concentra em todos os setores do Governo, desde as economias com o custeio da máquina pública até o ganho de escalas financeiras em grandes obras a serem construídas".

Analisando a literatura referente a eficiência e controle dos gastos públicos, identifica-se que a contabilidade de custos é colocada como um fator relevante. Dessa forma, existe um consenso entre os autores Fernandes (2011), Alonso (1999), Dias et al. (2009) e Junior (2015) que justificam essa relevância. Fernandes (2011) ressalta que com o gerenciamento de custos é possível ter controle e avaliar o gasto público. A partir daí, é possível mensurar a eficiência dos resultados obtidos utilizando indicadores de desempenho. Alonso (1999, p. 39), por sua vez, afirma que reconhecer custo nos serviços é "fundamental para atingir uma alocação eficiente de recursos. O desconhecimento dos custos é o maior indicador de ineficiência no provimento dos serviços públicos". No mesmo sentido, Dias et al. (2009, p. 373) comentam que "a gestão de custos na administração pública tem sido apontada como instrumento gerencial indispensável ao controle dos gastos públicos, como também avaliação de desempenho e economicidade". Por fim, Júnior (2015, p. 45) relata que a contabilidade de custos é "uma das mais importantes ferramentas para a busca da eficiência nos gastos públicos".

Outras formas de controle de gastos público são colocadas por Silva e Bonacim (2010, p. 153) como "os instrumentos de gestão por meio de orçamentos, normas orientadoras, leis rígidas e [...] órgãos fiscalizadores [...]”.

Analisando o cenário da pesquisa sobre eficiência dos gastos públicos, Diniz, Macedo e Corrar (2012, apud SILVA FILHO et al., 2016, p 55) afirmam que:

No Brasil, o número de pesquisas que abordam a eficiência na aplicação dos recursos públicos ainda é reduzido;

Uma das dificuldades enfrentadas quando se pretende analisar eficiência reside em definir uma métrica que consiga conjugar vários indicadores em um único, capaz de traduzir a eficiência da gestão pública; e

A idéia básica para se medir eficiência na aplicação de recursos públicos, consiste na definição de uma referência ou padrão para que seja possível fazer comparações com a finalidade de se questionar se algo está sendo eficiente ou ineficiente.

No combate ao desperdício dos recursos e a na redução dos custos, o IPEA (2006) reforça que a melhoria da qualidade do gasto público no Brasil irá ocorrer por meio de um dimensionamento e uma mensuração do desperdício de recursos públicos.

Outros posicionamentos sobre a eficiência dos gastos públicos que corroboram a pesquisa são o de Maia et al. (2009). O primeiro é a criação de redes de compartilhamento entre os órgãos, a fim propiciar o aprimoramento da administração dos recursos e permitir que ações com bom êxito sejam implementadas. O segundo, é que as boas práticas de gestão são fatores importantes que permitem à elevação da produtividade e da efetividade dos recursos empregados. Por fim, esses autores destacam que reavaliar e inovar os procedimentos de gestão governamental é uma forma de otimizar os recursos.

Sendo assim, o controle e eficiência dos gastos públicos relacionam uma série de estudos que devem ser adotados na gestão pública. Os de maior relevância mencionados nesta seção foram: o gerenciamento de custos, a mensuração por meio de indicadores, o emprego e compartilhamento de boas práticas de gestão, a reavaliação e inovação dos procedimentos de gestão governamental e a observância de normas regulamentadoras.

\subsection{O Projeto Esplanada Sustentável (PES)}

O PES é um projeto oficialmente instituído pela Portaria $n^{\circ} 244$, de 6 de junho de 2012, a partir de uma iniciativa conjunta dos MPOG, Minas e Energia e Desenvolvimento Social e Combate à Fome, que procuraram a integralização de ações realizadas e desenvolvidas de maneira isolada 
dentro de cada Ministério (MPOG, 2012). O MPOG destaca que a finalidade do projeto é "integrar ações que visam à melhoria da eficiência no uso racional dos recursos públicos e à inserção da variável socioambiental no ambiente de trabalho" (MPOG, 2012, p.1).

O PES possui sete objetivos, definidos pela Portaria Interministerial $n^{0} 244$, de 06 de junho de 2012, conforme abaixo:

I - promover a sustentabilidade ambiental, econômica e social na Administração Pública Federal;

II - melhorar a qualidade do gasto público pela eliminação do desperdício e pela melhoria contínua da gestão dos processos;

III - incentivar a implementação de ações de eficiência energética nas edificações públicas;

IV - estimular ações para o consumo racional dos recursos naturais e bens públicos;

$\mathrm{V}$ - garantir a gestão integrada de resíduos pós-consumo, inclusive a destinação ambientalmente correta;

VI - melhorar a qualidade de vida no ambiente do trabalho; $\mathrm{e}$

VII - reconhecer e premiar as melhores práticas de eficiência na utilização dos recursos públicos, nas dimensões de economicidade e socioambientais. (MPOG, 2012).

Vasconcelos e Nogueira (2014) destacam que o funcionamento do PES ocorre por meio de um Termo de Adesão com o MPOG com objetivo de deixar registrado o comprometimento dos órgãos públicos federais interessados em diminuir o uso de certos recursos naturais. Os autores enfatizam, ainda, que o projeto foi concedido visando, também, a economia de recursos, propondo a devolução de $50 \%$ do valor economizado pelos órgãos públicos por meio de um aumento do limite orçamentário-financeiro. Além disso, os respectivos valores são liberados após o órgão apresentar um Plano de Aplicação de Recursos contendo investimentos com ações sustentáveis a fim de gerar outras economias e reinicio de novo ciclo.

Iniciado por alguns órgãos públicos em Brasília, o PES teve sua expansão para todo o Poder Executivo Federal do país (VASCONCELOS; NOGUEIRA, 2014, p. 3). O autor destaca que o mesmo é considerado um projeto de Política Pública, pois é um programa ligado a agenda ambiental. Alguns projetos semelhantes ao PES são apresentados no Quadro 1.

\begin{tabular}{|c|c|c|}
\hline Estado & Projetos/Programas & Objetivo \\
\hline $\mathrm{R}$ & $\begin{array}{l}\text { Programa de Atitudes que Geram } \\
\text { Integração e Resultados (AGIR). }\end{array}$ & $\begin{array}{l}\text { "Racionalizar o gasto público por meio da promoção e } \\
\text { da integração de ações voltadas para a gestão eficiente } \\
\text { do gasto" (RS, 2013). } \\
\text { "Identificar os gastos por órgão, racionalizar as despesas } \\
\text { e reconhecer as melhores práticas administrativas e } \\
\text { sugestões para economia de recursos públicos e } \\
\text { ambientais" (FLORES et al., 2014, p. 113). }\end{array}$ \\
\hline $\mathrm{ES}$ & $\begin{array}{l}\text { Mais com menos - Programa de Controle e } \\
\text { Eficiência do Gasto Público. }\end{array}$ & $\begin{array}{l}\text { "Aumentar a eficiência do gasto preservando a qualidade } \\
\text { da prestação de serviço [...]" (VIEIRA et al., 2011, p.1). }\end{array}$ \\
\hline $\mathrm{SC}$ & 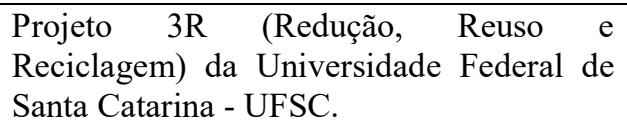 & $\begin{array}{l}\text { "Busca trabalhar com a prevenção e não geração de } \\
\text { resíduos sólidos, reduzindo a utilização de recursos } \\
\text { naturais" (SPÍNDOLA; LUIS NETTO; SOUZA, 2017). }\end{array}$ \\
\hline
\end{tabular}

Quadro 1: Projetos desenvolvidos semelhantes ao PES

Fonte: Os autores, 2018.

O Quadro 1 demonstra os projetos/programas desenvolvidos no Estado do Rio Grande do Sul/RS, Espírito Santo/ES e Santa Catarina/SC.

Por fim, o PES tem como perspectiva uma mudança de atitudes, comportamentos e opiniões quanto à utilização de forma eficiente dos recursos naturais pela administração pública. Além de proporcionar uma nova gestão na administração e execução dos recursos públicos (MPOG, 2012). 


\subsection{Avaliação de Projetos}

Avaliar consiste em mensurar, diferenciar, comparar, ato ou efeito de atribuir valor quantitativo ou qualitativo (SANTOS, 2002). Em face disso, a avaliação é um instrumento que auxilia os gestores públicos na tomada de decisões (COSTA; CASTANHAR, 2003, MOTTA, 2016). Santos (2002) complementa, ainda, que em um processo decisório não pode prescindir de instrumentos de avaliação. Nesse contexto, "o processo de gestão da empresa, consubstanciado nas fases de planejamento, execução e controle, requer avaliações desses desempenhos, como um requisito para o exercício da função controle" (SANTOS, 2002, p. 87).

Com relação à avaliação de projetos de gestão pública, o TCU (2010), órgão responsável pela fiscalização dos gastos públicos no Brasil, possui em seu Manual de Auditoria Operacional, o Diagrama de insumo-produto (Figura 1). O mesmo define os termos eficácia, eficiência e efetividade como medida para o desempenho operacional.

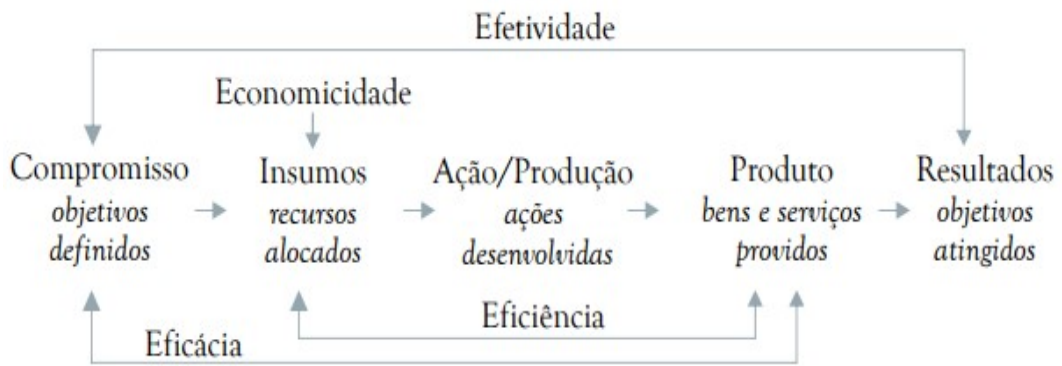

Figura 1: Diagrama de insumo-produto

Fonte: ISSAI 3000/1.4 (2004, Apud TCU, 2010)

Para atingir o objetivo proposto da pesquisa, o estudo irá enfatizar o termo efetividade. A Figura 1 destaca que a efetividade "diz respeito ao alcance dos resultados pretendidos, a médio e longo prazo" (TCU, 2010, p. 11). Além disso, Castro (2006) afirma que dentre as medidas de avaliação, a efetividade é mais abrangente que a eficácia, pois verifica se os objetivos foram atingidos.

Souto-Maior (2013) enfatiza que a efetividade de uma organização corresponde

à capacidade de definir e alcançar objetivos, que satisfaçam e promovam o bem estar aos seus exigentes internos e externos, para que seja efetiva a organização deve chegar a um entendimento com eles sobre normas, valores, objetivos e resultados, através de um diálogo que seja transparente, sem falsidades e sem coações; devendo envolver o maior número e variedade de exigentes possíveis.

A avaliação da dimensão econômico-financeira, em projetos públicos, foi mencionada no estudo de Mesquita (2016). O autor realizou uma avaliação utilizando o programa Bolsa Família. Foi apresentada uma análise do TCU sob a tríade orçamentária - objetivos e iniciativas do Plano Plurianual 2012-2015 e ações da Lei Orçamentária Anual 2014, comparando os objetivos propostos e os alcançados.

\section{METODOLOGIA}

A fim de avaliar os objetivos previstos no PES que estão em operação no âmbito do Instituto de Pesquisa Econômica Aplicada (IPEA), a metodologia desta pesquisa é apresentada sob o enfoque de três dimensões: natureza do objetivo, procedimentos e abordagem do problema. Quanto à natureza do objetivo, classifica-se como exploratória. As pesquisas exploratórias têm como objetivo "explorar ou fazer uma busca em um problema ou em uma situação a fim de oferecer informações e maior compreensão" (MALHOTRA, 2012, p. 59). Com relação aos procedimentos e para delinear a pesquisa, aplicou-se o estudo de caso. Yin $(2015$, p. 17) destaca que este tipo de pesquisa é "uma investigação empírica que investiga um fenômeno contemporâneo (o "caso") em profundidade e em seu contexto de mundo real, especialmente quando os limites entre o fenômeno e o contexto puderem não ser claramente evidentes". Por fim, quanto à abordagem do problema, o estudo é 
qualitativo. Malhotra (2012, p. 110) argumenta que a pesquisa qualitativa "proporciona melhor visão e compreensão do contexto do problema"

Para atingir o objetivo proposto e para proporcionar maior confiabilidade das informações e dos dados coletados, a metodologia busca contemplar as etapas do estudo, desde a fundamentação teórica, passando pela coleta e análise dos dados, discussão dos resultados e pelas conclusões da pesquisa.

Para maior confiabilidade das informações e dados da pesquisa, foi elaborado um protocolo de pesquisa. Segundo Yin (2015, p. 88) o protocolo tem como objetivo "orientar o pesquisador na realização da coleta de dados". A Figura 2 apresenta o protocolo da pesquisa com suas respectivas etapas.

\begin{tabular}{|c|c|c|c|}
\hline Informações iniciais & Coleta dos dados & Tratamento dos dados & Análise dos resultados \\
\hline$\downarrow$ & $\downarrow$ & $\downarrow$ & 1 \\
\hline $\begin{array}{l}\text { Escolha do órgão a ser } \\
\text { analisado para atingir o } \\
\text { objetivo proposto do } \\
\text { estudo } \\
\text { Fundamentação Teórica. } \\
\text { Metodologia: tipo de } \\
\text { pesquisa, coleta de dados } \\
\text { e tratamento dos dados. }\end{array}$ & $\begin{array}{l}\text { Pesquisa documental } \\
\text { direta. } \\
\text { Entrevistas. } \\
\text { Questionários } \\
\text { Relatórios gerenciais. }\end{array}$ & \begin{tabular}{ll}
\multicolumn{2}{l}{ Sistematização } \\
dados por & meio do \\
programa & Microsoft \\
Excel. &
\end{tabular} & $\begin{array}{l}\text { Perfil dos respondentes. } \\
\text { Percepção sobre a } \\
\text { implantação do PES. } \\
\text { Análise do atingimento } \\
\text { dos objetivos do PES. } \\
\text { Análise estratégica do } \\
\text { PES. Contribuições } \\
\text { para práticas } \\
\text { sustentáveis. }\end{array}$ \\
\hline
\end{tabular}

Figura 2: Protocolo do estudo de caso

Fonte: os autores com base em YIN (2015)

Na etapa 1, a pesquisa definiu o estudo de caso para avaliar os objetivos previstos no PES e uma revisão bibliográfica, exposta na fundamentação teórica. O órgão escolhido para avaliação do atingimento dos objetivos previstos no PES foi o Instituto de Pesquisa Econômica Aplicada (IPEA), fundação pública federal vinculada ao MPOG, com sede em Brasília/DF e Rio de Janeiro/RJ e por ser uma das primeiras instituições a adotarem medidas de sustentabilidade e eficiência no uso de recursos naturais. O IPEA é uma instituição que realiza atividades de pesquisa a fim de "fornecer suporte técnico e institucional às ações governamentais para a formulação e reformulação de políticas públicas e programas de desenvolvimento brasileiros" (IPEA, 2018).

$\mathrm{Na}$ etapa 2, realizou-se o estudo de caso do PES. As coletas de dados foram-efetuadas por meio de pesquisa documental direta, entrevistas, questionários e relatórios gerenciais. Na pesquisa documental direta ocorreram análises dos seguintes documentos: Portaria Interministerial n. 244, de 6 de junho de 2012, do MPOG que instituiu o PES cuja a finalidade é "integrar ações que visam à melhoria da eficiência no uso racional dos recursos públicos e à inserção da variável socioambiental no ambiente de trabalho" (MPOG, 2012), Acórdão n. 1.752/2011, do TCU que estabelece uma integração de ações da administração pública referente ao "uso racional e sustentável de recursos naturais" (TCU, 2011) e Relatório de Auditoria do TCU n. TC 026.652/2013-7, que trata do exame de monitoramento sobre o cumprimento do Acórdão 1.752/2011-TCU-Plenário (TCU, 2013). As entrevistas ocorreram no IPEA/RJ, no dia 26 de outubro de 2017, com base em um roteiro elaborado através dos documentos analisados na pesquisa documental direta. Foram entrevistados a Líder do PES no IPEA/RJ e dois gestores para que os mesmos pudessem externar suas percepções e experiências práticas na gestão do projeto. Não foram realizadas entrevistas com o Líder do PES e gestores do IPEA/DF. Os questionários foram aplicados em novembro de 2017 e buscou-se identificar a percepção dos gestores e servidores/colaboradores. Por intermédio da equipe do IPEA, os mesmos foram enviados aos gestores e servidores/colaboradores por meio de um email contendo 
um link do Google Drive Formulário. De acordo com Mathias e Sakai $(2013$, p. 7) utilizando o Google Forms "o formulário construído pode ser disponibilizado através de um endereço eletrônico e, em quando preenchido pelos respondentes, as respostas aparecem imediatamente na página do Google Forms do usuário que os criou". Os respondentes dos dois questionários efetuaram suas respostas de forma anônima.

O primeiro questionário destinou-se aos gestores do PES, apresentando as seguintes seções: 1.Termo de Consentimento Livre e Esclarecido (TCLE); 2.Perfil dos Respondentes; 3.Processo de Implantação do PES; 4. Avaliação de metas e ações do PES; 5.Avaliação do Impacto do PES; 6.Gestão e Administrativa da sustentabilidade e eficiência; e 7.Agradecimento. Já o segundo questionário destinou-se aos servidores/colaboradores, apresentando as seguintes seções: 1.Termo de Consentimento Livre e Esclarecido (TCLE); 2.Perfil dos respondentes; 3.Percepção dos respondentes para alguns aspectos relacionados ao PES; e 4.Agradecimento. Posteriormente, realizou-se análise documental referente ao PES por meio dos relatórios gerenciais disponibilizados pelo IPEA-RJ.

O roteiro da entrevista e os questionários dos gestores e servidores/colabores foram criados pelos pesquisadores e estão apresentados com detalhe nos Apêndices A, B e C, respectivamente. Para objetivar a seleção dos sujeitos da amostra, a pesquisa considerou o quantitativo de integrantes que participaram da pesquisa. Ao final, a amostra ficou composta por 74 sujeitos, classificados em gestores e servidores /colaboradores.

De posse dos questionários respondidos foi realizado o tratamento dos dados (etapa 3). Diante disso, os dados foram analisados com o auxílio do programa Microsoft Excel por meio de gráficos e tabelas dinâmicas. As informações referentes ao perfil dos respondentes foram verificadas por meio das percentagens de observações obtidas em cada variável. Seguindo as recomendações de Matrotra (2012), a avaliação da percepção dos gestores sobre a implantação do PES foi realizada considerando as questões ordenadas em escala likert. Para avaliar o atingimento dos objetivos do PES, o estudo procedeu-se à observação das respostas abertas e fechadas dos questionários aplicados. Além disso, a análise estratégia do PES foi realizada por meio da matriz SWOT.

\section{ANÁLISE DOS RESULTADOS}

A análise dos resultados está organizada em quatro subseções. Na primeira seção, foi analisado o perfil dos respondentes; na segunda seção, a percepção dos gestores sobre a implantação do PES; na terceira seção, foram examinados os resultados do atingimento dos objetivos do PES; e, por fim, na quarta seção, é verificada a análise estratégica do PES. Dessa forma, conforme descrito na seção de procedimentos metodológicos, após a aplicação dos questionários, foram obtidas 10 respostas dos gestores e 64 respostas de servidores/colaboradores para análise dos dados.

\subsection{Perfil dos Respondentes}

A análise do perfil dos respondentes foi efetuada com base nas informações dos questionários dos gestores e servidores/colaboradores. A Tabela 1 apresenta os resultados. 
Tabela 1: Distribuição quanto ao sexo, nível de escolaridade e tempo na Instituição

\begin{tabular}{lcc}
\hline \multicolumn{1}{r}{ Variável } & Gestores & Colaboradores/Servidores \\
\cline { 2 - 3 } & $\mathbf{n}(\mathbf{\%})$ & $\mathbf{n}(\mathbf{\%})$ \\
\hline Sexo & $3(30 \%)$ & $34(53 \%)$ \\
Masculino & $7(70 \%)$ & $30(47 \%)$ \\
Feminino & & \\
\hline Nível de Escolaridade & - & $1(1,6 \%)$ \\
Ensino médio & - & $5(7,8 \%)$ \\
Superior incompleto & $1(10 \%)$ & $21(32,8 \%)$ \\
Superior completo & $9(90 \%)$ & $37(57,8 \%)$ \\
Pós-graduado & & $17(26,6 \%)$ \\
\hline Tempo na Instituição & - & $15(23,4 \%)$ \\
Até 1 ano & $2(20 \%)$ & $15(23,4 \%)$ \\
De 1 a 5 anos & $4(40 \%)$ & $17(26,6 \%)$ \\
De 5 a 10 anos & $4(40 \%)$ & \\
Mais de 10 anos & &
\end{tabular}

Fonte: os autores, 2018

No primeiro questionário, quanto ao gênero dos gestores participantes da pesquisa, $70 \%$ são do sexo feminino e $30 \%$ do sexo masculino. Com relação a escolaridade, $90 \%$ possuem pósgraduação e $10 \%$ possuem nível superior completo. E, na questão do tempo na Instituição, 20\% possuem de 1 a 5 anos, $40 \%$ possuem de 5 a 10 anos e $40 \%$ possuem mais de 10 anos, conforme tabela 1 .

No segundo questionário, quanto ao gênero dos servidores/colaboradores participantes da pesquisa, $47 \%$ são do sexo feminino e $53 \%$ do sexo masculino. Com relação a escolaridade, $58 \%$ possuem pós-graduação e 33\% possuem nível superior completo, $8 \%$ possuem nível superior incompleto e $2 \%$ possuem nível médio. E, na questão do tempo na Instituição, $27 \%$ possuem até 1 ano, $23 \%$ possuem de 1 a 5 anos, $23 \%$ possuem de 5 a 10 anos e $27 \%$ possuem mais de 10 anos, conforme tabela 2 .

\subsection{Percepção dos Gestores Sobre a Implantação do PES}

Para entendimento do processo de implantação do PES, o estudo realizou uma análise de conteúdo das perguntas realizadas, a saber: 1. "A cultura dos colaboradores foi uma barreira para o processo de implementação?”; 2.“A mensuração dos recursos foi uma barreira para o processo de implementação?"; e 3."Houve dificuldades na implantação do PES. Se sua resposta for sim, quais foram as dificuldades?"

Nas perguntas 1 e 2, procedeu-se à verificação das respostas efetuadas em escala likert. A Figura 3 apresenta os resultados.

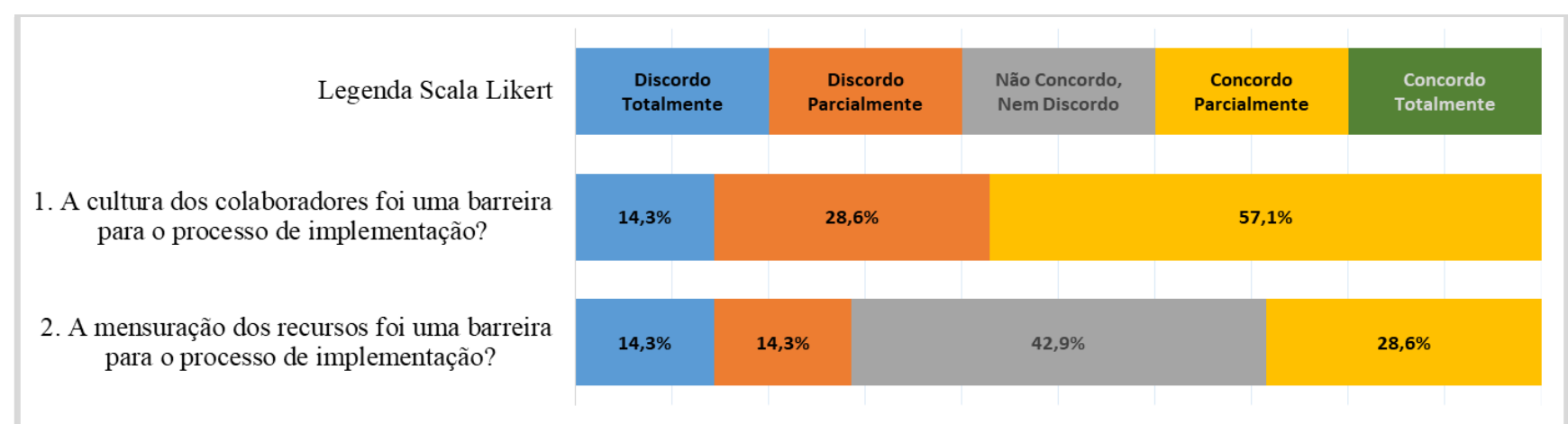

Figura 3: Percepção dos gestores sobre a implantação do PES

Fonte: Os autores

ISSN 2595-7287 | RCGC | UFF | Niterói/RJ | V.1 | n.2 | jul-dez. 2018 | p. 3-20 
Observa-se, na Figura 3, que 57,1\% dos gestores concordaram, parcialmente, que a cultura dos colaboradores foi uma barreira para a implementação do PES. Em continuação, a terceira pergunta, apresentada de forma aberta, objetivou verificar as dificuldades na implantação do projeto. As principais dificuldades mais mencionadas pelos gestores foram: falta de pessoal, falta de recursos orçamentários, resistência cultural, adaptação e processos burocráticos.

\subsection{Atingimento dos Objetivos do PES}

A análise do atingimento dos objetivos do PES no IPEA foi avaliada por meio dos questionários aplicados aos gestores e servidores/colaboradores. Para mensurar o atingimento (ou não) dos objetivos previstos, a coluna "Atingimento" (Quadros 2 e 3) abordou os seguintes termos: Pleno - quando identificado que o objetivo foi atendido em sua totalidade; Parcial - quando o objetivo foi atendido parcialmente; e Nulo - quando o objetivo não foi atingido em nenhum grau. A análise dos respectivos termos foi realizada considerando as informações inseridas na coluna "Percepção dos gestores" (Quadro 2) e "Percepção dos civis/colaboradores" (Quadro 3).

Com relação ao questionário aplicado aos Gestores do PES (Apêndice B), o Quadro 2 apresenta os resultados da avaliação do PES no IPEA, em face das questões Q7 a Q14, que correspondem aos objetivos I, II, III, V, VI e VII.

\begin{tabular}{|c|c|c|}
\hline Objetivos do PES & Percepção dos gestores & Atingimento \\
\hline $\begin{array}{l}\text { Objetivo I - promover a } \\
\text { sustentabilidade } \\
\text { ambiental, econômica e } \\
\text { social na Administração } \\
\text { Pública Federal. }\end{array}$ & $\begin{array}{l}\text { O IPEA vem promovendo, parcialmente, ações } \\
\text { positivas de sustentabilidade ambiental e } \\
\text { socioeconômica. As principais ações foram: } \\
\text { Ação ambiental: redução de alguns dos recursos } \\
\text { naturais utilizados. } \\
\text { Ação econômica: redução do gasto público a } \\
\text { partir de mudanças de atitudes e hábitos. } \\
\text { Ação social: o relacionamento com as } \\
\text { cooperativas e a conscientização das pessoas vem } \\
\text { promovendo uma sustentabilidade em âmbito } \\
\text { social. } \\
\text { Uma limitação apontada foi que as medidas de } \\
\text { ações racionais de recursos naturais são poucas, } \\
\text { pois muitas delas dependem de reformas em } \\
\text { infraestrutura dos edifícios. }\end{array}$ & $\begin{array}{l}\text { Parcial. } \\
\text { Apesar de existirem ações de } \\
\text { sustentabilidade ambiental, } \\
\text { econômica e social, a pesquisa } \\
\text { identificou que para atingir este } \\
\text { objetivo o órgão deve realizar } \\
\text { reformas em infraestrutura no } \\
\text { prédio. Cita-se a falta da } \\
\text { capacidade de mensurar o } \\
\text { consumo de água. }\end{array}$ \\
\hline $\begin{array}{l}\text { Objetivo II - melhorar a } \\
\text { qualidade do gasto } \\
\text { público pela eliminação } \\
\text { do desperdício e pela } \\
\text { melhoria contínua. }\end{array}$ & $\begin{array}{l}\text { A cultura social foi um dos fatores que } \\
\text { contribuíram para a melhoria da qualidade do } \\
\text { gasto público. } \\
\text { Necessidade de melhoria na gestão dos processos. } \\
\text { No entanto, alguns relatos apontaram a } \\
\text { descontinuidade das ações do projeto. }\end{array}$ & $\begin{array}{l}\text { Parcial. } \\
\text { A não continuidade das iniciativas } \\
\text { do PES corroboram para o } \\
\text { atingimento parcial do objetivo. } \\
\text { Como exemplo, o estudo destaca: } \\
\text { a volta da utilização de papel } \\
\text { comum e a falta de reuniões do } \\
\text { projeto para melhoria dos } \\
\text { processos. }\end{array}$ \\
\hline $\begin{array}{l}\text { Objetivo III } \text { - } \text { incentivar } \\
\text { a implementação de } \\
\text { ações de eficiência } \\
\text { energética } \\
\text { edificações públicas. nas }\end{array}$ & $\begin{array}{l}\text { Campanha contra o desperdício de energia } \\
\text { elétrica. } \\
\text { Substituição dos equipamentos antigos (ar- } \\
\text { condicionados) Em função disso, houve uma } \\
\text { redução do consumo de energia elétrica. } \\
\text { Torneiras com sensores nos banheiros. }\end{array}$ & $\begin{array}{l}\text { Parcial. } \\
\text { Embora o estudo tenha observado } \\
\text { fatores que contribuem com a } \\
\text { eficiência energética, a falta de } \\
\text { recursos para o projeto é vista } \\
\text { como uma limitação para atingir } \\
\text { este objetivo. }\end{array}$ \\
\hline Continua... & & \\
\hline
\end{tabular}




\begin{tabular}{|c|c|c|}
\hline $\begin{array}{l}\text { Objetivo } \mathrm{V} \text { - garantir a } \\
\text { gestão integrada de } \\
\text { resíduos pós-consumo, } \\
\text { inclusive a destinação } \\
\text { ambientalmente correta. }\end{array}$ & $\begin{array}{l}\text { Existe um processo de gestão integrada por meio } \\
\text { de coleta seletiva. Entretanto, foi apontado que os } \\
\text { serviços de coleta seletiva por meio de } \\
\text { cooperativa são burocráticos. A contratação e } \\
\text { continuidade dos mesmos exigem processo } \\
\text { licitatório. }\end{array}$ & $\begin{array}{l}\text { Pleno. } \\
\text { A gestão integrada por meio de } \\
\text { coleta seletiva corrobora para o } \\
\text { atingimento total do objetivo. }\end{array}$ \\
\hline $\begin{array}{l}\text { Objetivo VI -melhorar a } \\
\text { qualidade de vida no } \\
\text { ambiente do trabalho. }\end{array}$ & $\begin{array}{l}\text { Integração social e salubridade dos ambientes. } \\
\text { Substituição de equipamentos mais antigos por } \\
\text { mais modernos. }\end{array}$ & $\begin{array}{l}\text { Pleno } \\
\text { A integração social e a } \\
\text { salubridade dos ambientes } \\
\text { corroboram para o atingimento } \\
\text { total do objetivo. }\end{array}$ \\
\hline $\begin{array}{l}\text { Objetivo } \\
\text { reconhecer e premiar as } \\
\text { melhores práticas de } \\
\text { eficiência na utilização } \\
\text { dos recursos públicos, } \\
\text { nas dimensões de } \\
\text { economicidade } \\
\text { socioambientais. }\end{array}$ & $\begin{array}{l}\text { Não foi observado nenhum tipo de premiação ou } \\
\text { reconhecimento pelas práticas de eficiência dos } \\
\text { recursos. }\end{array}$ & $\begin{array}{l}\text { Nulo } \\
\text { A falta de reconhecimento pelas } \\
\text { práticas de eficiência dos recursos } \\
\text { corrobora para o não atingimento } \\
\text { do objetivo em nenhum grau. }\end{array}$ \\
\hline
\end{tabular}

Quadro 2: Atingimento dos objetivos do PES no IPEA

Fonte: os autores, 2018

Conforme Quadro 2, a pesquisa aponta que apenas os objetivos V e VI foi atingido em sua totalidade. Além disso, constata-se que os objetivos previstos no PES relacionam-se com outros programas semelhantes, tais como: Programa de Qualidade do Gasto Público, Programa de Atitudes que Geram Integração e Resultados (AGIR), Mais com menos - Programa de Controle e Eficiência do Gasto Público e Projeto 3R (Redução, Reuso e Reciclagem) da Universidade Federal de Santa Catarina - UFSC (RIO GRANDE DO SUL, 2013; FLORES et al., 2014; VIEIRA et al., 2011; SPINDOLA; LUIS NETTO; SOUZA, 2017).

A verificação do atingimento (ou não) do objetivo IV foi realizada por meio da análise das informações contidas nas questões Q4 a Q8 integrantes do questionário aplicado aos servidores/colaboradores (Apêndice C). Por meio das respostas existentes nas questões Q4 a Q7, a Figura 4 apresenta a percepção sobre os estímulos de ações para o consumo racional dos seguintes itens, quais sejam: energia elétrica, bens imóveis, água, copo plástico e papel.

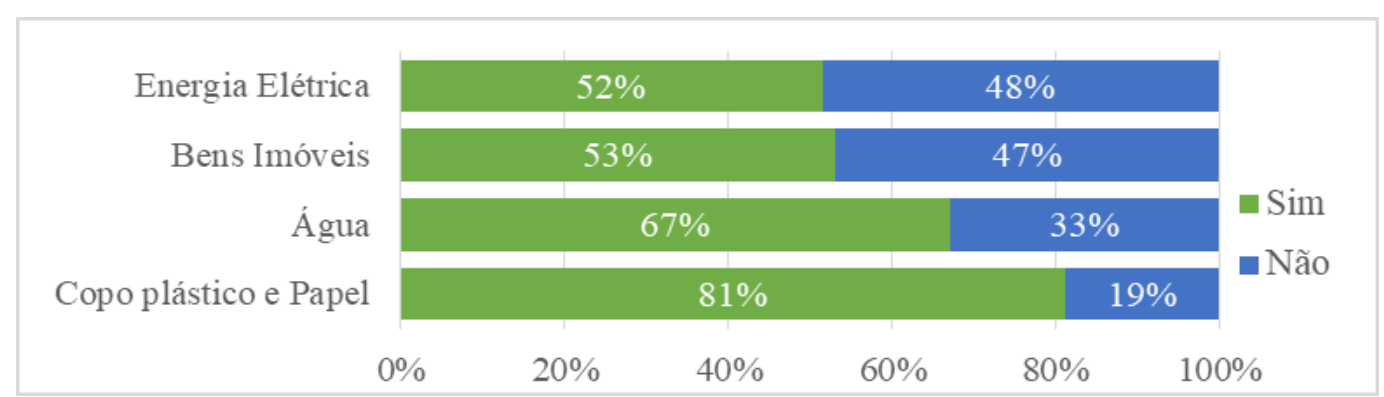

Figura 4: Percepção dos Servidores/Colaboradores sobre os estímulos aos recursos Fonte: Os autores, 2018

A pesquisa aponta que os itens com mais estímulos são a utilização racional de copo plástico e papel com $81 \%$ e água com $67 \%$. Em seguida, considerando a questão Q8, a Figura 5 apresenta o resultado das práticas utilizadas pelo o IPEA para estimular a economia de recursos. 


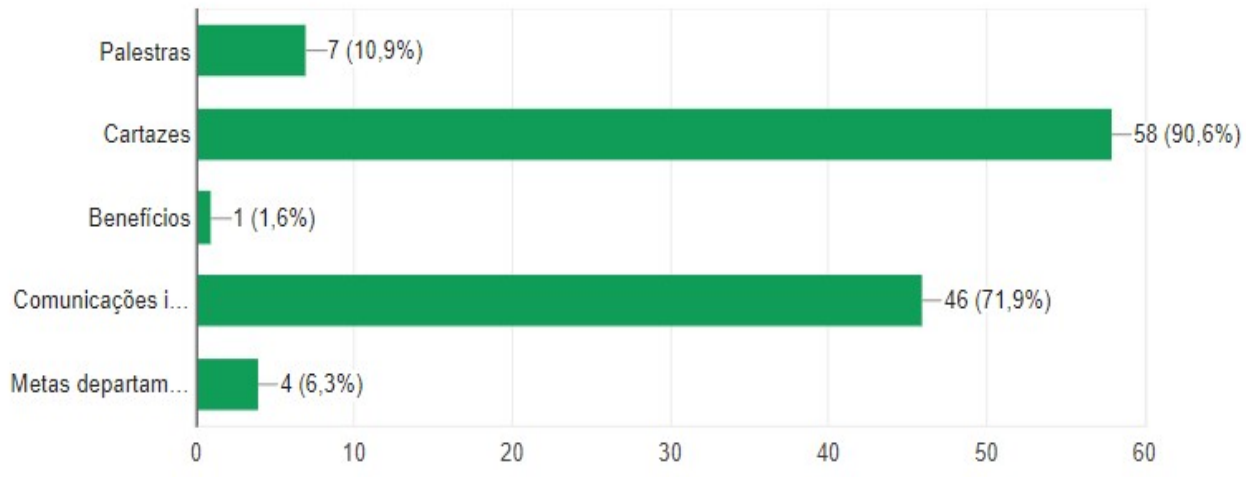

Figura 5: Práticas para estimular a economia dos recursos

Fonte: os autores, 2018

A prática mais adotada pelo IPEA para estimular a economia dos recursos é por meio de cartazes (90,6\%), seguida de comunicação interna (71,9\%). Sendo assim, o Quadro 3 descreve a consolidação dos resultados do PES, que corresponde ao objetivo IV.

\begin{tabular}{|c|c|c|}
\hline Objetivos do PES & Percepção dos servidores/colaboradores & Atingimento \\
\hline 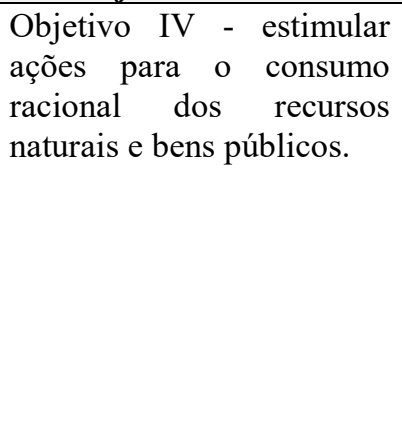 & $\begin{array}{l}\text { Estímulos para a utilização racional dos itens: energia } \\
\text { elétrica, bens imóveis, água, copo plástico e papel. } \\
\text { Resultados: o estímulo para utilização racional de copo } \\
\text { plástico e papel foi percebido por } 81 \% \text { dos servidores e } \\
\text { colaboradores. Já o estímulo para utilização racional de } \\
\text { energia elétrica apontou apenas } 52 \% \text {. } \\
\text { Práticas para estimular a economia dos recursos } \\
\text { Resultados: somente duas práticas (cartazes e } \\
\text { comunicações internas) foram mencionadas pela } \\
\text { maioria dos respondentes como estímulo para } \\
\text { economia de recursos. }\end{array}$ & \begin{tabular}{lrr} 
Parcial & \\
Um fator & \multicolumn{2}{c}{ importante } \\
observado no & estudo que \\
corroborou & para & o \\
atingimento parcial do & pbjetivo foi que apenas & $52 \%$ \\
objo & dos servidores/colaboradores \\
verificaram o estímulo à \\
utilização racional de \\
energia elétrica.
\end{tabular} \\
\hline
\end{tabular}

Quadro 3: Atingimento do objetivo IV do PES no IPEA

Fonte: os autores, 2018

O Quadro 3 demonstra que o objetivo IV - estimular ações para o consumo racional dos recursos naturais e bens públicos - não foi atingindo em sua totalidade. Conforme MPOG (2012), o PES permite constatar a utilização de forma eficiente dos recursos públicos. O referido Ministério aponta que o PES proporciona uma nova gestão na administração e execução dos recursos públicos. Nesse sentido, Grateron (1999) assevera que o controle é um elemento fundamental para o cumprimento de metas em uma gestão pública. Aliás, é por meio de uma ação preventiva e corretiva, que a Administração Pública concretizará os objetivos traçados. Além disso, as práticas de gestão, quando executadas de forma adequada, permitem à elevação da produtividade e efetividade dos recursos empregados (MAIA et al., 2009).

\subsection{Análise Estratégica do PES}

Para integrar os resultados e contribuir com uma análise estratégica do PES, utilizou-se a análise SWOT, criada "pela escola do design, do grupo de administração geral da Harvard Business School” (CHRISTENSEN; BOWER, 1965 apud TCU, 2010, p. 4). Neste contexto, o Quadro 4, Análise da Matriz SWOT do PES, apresenta uma síntese do resultado da pesquisa.

A análise estratégia Matriz SWOT, um acrônimo formado pelas palavras inglesas Strengths (forças), Weaknesses (fraquezas), Opportunities (oportunidades) e Threats (ameaças), que "resultam em uma lista de prós e contras que auxiliam na tomada de decisão" (TCU, 2010, p. 5). Além disso, por meio da análise da Matriz SWOT "os gerentes conseguem elaborar estratégias para obter vantagem competitiva e melhorar o desempenho organizacional” (SILVA et al. 2011). 
Com base nos dados coletados, o Quadro 4 apresenta a matriz SWOT do PES.

\begin{tabular}{|c|c|c|c|}
\hline & \multicolumn{2}{|c|}{ Análise SWOT } & \\
\hline+ & Forças & Fraquezas & - \\
\hline & $\begin{array}{l}\text { Equipamentos mais modernos; coleta seletiva; } \\
\text { redução do uso de copos plásticos; uso de papel } \\
\text { reciclável; torneiras com sensores; utilização de } \\
\text { lâmpadas econômicas; economia de energia; } \\
\text { redução de gasto público; e inserção do termo } \\
\text { sustentabilidade no ambiente de trabalho. }\end{array}$ & $\begin{array}{l}\text { Processos burocráticos; recursos orçamentários e } \\
\text { financeiros limitados; poucas ações de } \\
\text { conscientização; necessidade de rever o planejamento; } \\
\text { necessidade de monitoramento do PES; os resultados } \\
\text { do projeto são poucos divulgados; a conscientização } \\
\text { das pessoas sobre a importância do projeto é } \\
\text { demorada; e descontinuidade das ações iniciais do } \\
\text { PES. }\end{array}$ & \\
\hline+ & Oportunidades & Ameaças & - \\
\hline & $\begin{array}{l}\text { Implementação do sistema eletrônico de } \\
\text { informação; contratação de cooperativas; } \\
\text { eficiência de gestão; mudança de hábitos; e } \\
\text { compras sustentáveis. }\end{array}$ & $\begin{array}{l}\text { Mudança na gestão; rotatividade de servidores; } \\
\text { infraestrutura dos edifícios; resistência cultural; e } \\
\text { exigências legislativas para o recolhimento de } \\
\text { resíduos. }\end{array}$ & \\
\hline
\end{tabular}

Quadro 4: Análise da Matriz SWOT do PES

Fonte: Os autores, 2018

Diante disso, a melhoria da qualidade do gasto irá ocorrer a partir de um dimensionamento e uma mensuração do desperdício de recursos públicos (IPEA, 2006).

\section{CONSIDERAÇÕES FINAIS}

A pesquisa avaliou as práticas sustentáveis de gestão e os objetivos previstos no PES, a fim constatar se o respectivo projeto está sendo gerenciado e operacionalizado corretamente, ou seja, mensurando a sua efetividade, que visa o controle e a eficiência dos recursos públicos, como medida de sustentabilidade socioambiental. Após uma revisão da literatura, aplicou-se questionários que foram submetidos aos gestores e servidores/colaboradores do Instituto de Pesquisa Econômica Aplicada (IPEA/RJ).

No que diz respeito aos resultados descritos da efetividade do PES, dos sete objetivos analisados, quatro foram atingidos de forma parcial, dois foram atingidos de forma plena, e um objetivo não foi atingido em nenhum grau, denominando-se como atingimento nulo.

No tocante a primeira classificação, a parcial, conforme o Quadro 2, os objetivos de (I) promover a sustentabilidade ambiental, econômica e social na Administração Pública Federal; (II) melhorar a qualidade do gasto público pela eliminação do desperdício e pela melhoria contínua; (III) incentivar a implementação de ações de eficiência energética nas edificações públicas; e, conforme Quadro 3, (IV) incentivar a implementação de ações de eficiência energética nas edificações públicas, foram parcialmente atingidos, deixando assim uma lacuna para se compreender os fatores que levaram ao atingimento parcial.

Ainda, conforme o Quadro 2, no tocante a classificação plena, os objetivos de (V) garantir a gestão integrada de resíduos pós-consumo, inclusive a destinação ambientalmente correta; e, (VI) melhorar a qualidade de vida no ambiente do trabalho foram atingidos de forma plena, pois, conforme análise da pesquisa, a gestão integrada por meio de coleta seletiva, a integração social e a salubridade dos ambientes corroboram para o atingimento total dos objetivos. Nesse aspecto, o estudo identificou uma mudança nas práticas de gestão da instituição após a implementação do projeto.

Por fim, quanto ao objetivo de (VII) reconhecer e premiar as melhores práticas de eficiência na utilização dos recursos públicos, nas dimensões de economicidade e socioambientais; não foi atingido em nenhum grau, tendo em vista que não houve relato ou indício dessa prática de gestão.

No que tange a análise estratégica do PES, por meio da matriz SWOT, verificou-se que as fraquezas descritas devem ser trabalhadas pelos gestores do PES para que haja um aumento da efetividade do projeto, como: ações de conscientização; revisão do planejamento; monitoramento; 
divulgação dos resultados; e os processos burocráticos. Além disso, necessita-se de um aprofundamento de estudo no ambiente externo que poderá ser útil aos interesses da organização.

A pesquisa foi limitada à análise do atingimento dos objetivos do PES no Instituto de Pesquisa Econômica Aplicada (IPEA). Buscando aprofundar e complementar novas descobertas sobre o projeto, sugere-se ampliar este estudo para outras entidades da Administração Pública Federal com objetivo de contribuir para a avaliação de projetos que visam a eficiência dos recursos públicos. Por fim, para estudos futuros, sugere-se identificar os fatores que contribuíram para o não atingimento dos objetivos e o impacto provocado pelas propostas de mudanças das práticas de gestão com relação ao aspecto de sustentabilidade socioambiental.

\section{REFERÊNCIAS}

ALONSO, M. Custos no serviço público. Revista do Serviço Público, Brasília, v. 50, n. 1, p. 3763, 1999.

CASTRO, R. B. Eficácia, Eficiência e Efetividade na administração pública. In ENCONTRO NACIONAL E PÓS GRADUAÇÃO E PESQUISA EM ADMINISTRAÇÃO, 30., 2006, Salvador. Anais... Salvador.

COSTA, F. L.; CASTANHAR, J. C. Avaliação de programas públicos: desafios conceituais e metodológicos. Revista de Administração Pública, Rio de Janeiro, v. 37, n. 5, p. 969-92, 2003.

DIAS, H. L.; GONDRIGE, E. O.; CLEMENTE, A., ESPEJO, M. M. S. B.; VOESE, S. B. Custos no Setor Público: A percepção dos Controladores de Recursos Públicos do Estado de Santa Catarina. Revista del Instituto Internacional de Costos, n. 5, p. 373-399, 2009.

ESTADO DO RIO GRANDE DO SUL-RS. Decreto $\mathrm{n}^{\circ}$ 50.183, de 25 de março de 2013. Institui o Programa de Qualidade do Gasto. Disponível em: $<$ http://www.al.rs.gov.br/filerepository/repLegis/arquivos/DEC\%2050.183.pdf $>$. Acesso em: 27 nov. 2017.

FERNANDES, J. C. C. O. Uso da Informação de Custos na busca pela Excelência da Gestão Pública. In: CONGRESSO DE GESTÃO PÚBLICA, 4., 2011, Brasília. Anais... Brasília.

FIGUEIREDO, M. F.; FIGUEIREDO, A. M. C. Avaliação política e avaliação de políticas: um quadro de referência teórica. Revista Fundação João Pinheiro, Belo Horizonte, v. 1, n. 3, p. 108129, 1986.

FLORES, L.; NOVA, R. L. V.; VIEIRA, C. M.; SANTOS, M. M; ANESE, R. R. Qualidade nos gastos públicos: um enfoque no Programa Agir, do Ministério Público-RS. Revista Administração Gestão Estratégica, v. 7, n. 2, p. 111-118, 2014.

GRATERON, I. R. G. Auditoria de gestão: utilização de indicadores de gestão no setor público. Caderno de estudos - FIPECAFI, São Paulo, n. 21, p. 01-18, 1999.

INSTITUTO DE PESQUISA ECONÔMICA APLICADA-IPEA. Boletim de Desenvolvimento Fiscal, $\quad$ n. $3, \quad$ p. $1-65, \quad 2006 . \quad$ Disponível em: $<$ http://www.ipea.gov.br/portal/images/stories/PDFs/Boletim_desenv_fiscal/bdf_03.pdf $>$. Acesso em: 01 jun. 2017.

. Blog do IPEA. Disponível em: <http://www.ipea.gov.br>. Acesso em: 24 jun. 2018.

JUNIOR, V. V. Gestão de Custos para Qualidade e Eficiência dos Gastos Públicos: Mapeamento da Percepção dos Gestores Públicos e Contadores da Região Metropolitana de Campinas (RMC). Dissertação (Mestrado em Ciências Contábeis) - Fundação Escola de Comércio Álvares Penteado, São Paulo, 2015. 
MAIA, A.; VALLE, A.; FROSSARD, L. B. M.; CAMPOS, L. K.; MELO, L.; CARVALHO, M. A. B. A importância da melhoria da qualidade do gasto público no Brasil: Propostas práticas para alcançar este objetivo. In: Congresso Consad de Gestão Pública, 2, 2009. Anais... Brasília.

MALHOTRA, N. K. Pesquisa de marketing: Uma orientação aplicada. 6. Ed. Porto Alegre: Bookman, 2012.

MALENA. D. C. C. Q.; JOSÉ FILHO, A. B.; OlIVEIRA, J. H.; CASTRO, D. T. Análise Situacional da Eficiência do Gasto Público com despesas administrativas no Governo do Estado do Tocantins. In: CONGRESSO CONSAD DE GESTÃO PÚBLICA, 6., 2013, Brasília, Anais... Brasília.

MATHIAS, S. L.; SAKAI, C. Utilização da Ferramenta Google Forms no Processo de Avaliação Institucional: Estudo de Caso nas Faculdades Magsul. In: SEMINÁRIO REGIONAL SOBRE AUTOAVALIAÇÃO INSTITUCIONAL E COMISSÕES PRÓPRIAS DE AVALIAÇÃO (CPA), 2013, Região Centro-Oeste. Anais... Região Centro-Oeste, 2013.

MESQUITA, C. F. M. O papel do direito na articulação governamental necessária às políticas públicas: Uma avaliação do Programa Bolsa Família (PBF). Cadernos Gestão Pública e Cidadania, São Paulo, v. 21, n. 70, 2016.

MINISTÉRIO DO PLANEJAMENTO, ORÇAMENTO E GESTÃO- MPOG. Portaria Interministerial $n^{\circ}$ 244, de 6 de junho de 2012. Institui o Projeto Esplanada Sustentável - PES, cuja finalidade é integrar ações que visam à melhoria da eficiência no uso racional dos recursos públicos e à inserção da variável socioambiental no ambiente de trabalho. Brasília, DF. Disponível em: <http://bibspi.planejamento.gov.br/handle/iditem/373>. Acesso em: 02 abr. 2017.

MOTTA, R. A. Método para a determinação da sustentabilidade de ciclovias. Tese (Doutorado em Transportes) - Universidade de Brasília, Brasília, 2016.

PEREIRA, L. C. B. Reforma da nova gestão pública: agora na agenda da América Latina, no entanto... Revista do Serviço Público, Brasília, v. 1, n. 2, p. 5-27, 2002.

SANTOS, L. P. G. Uma contribuição à discussão sobre a avaliação de desempenho das instituições federais de ensino superior: uma abordagem da gestão econômica. Revista Contabilidade \& Finanças, São Paulo, v. 13, n. 28, p. 86-99, 2002.

SILVA, A. A.; SILVA, N. S. D.; BARBOSA, V. D. A.; HENRIQUE, M. R.; BAPTISTA, J. A. A utilização da matriz SWOT como ferramenta estratégica-um estudo de caso em uma escola de idioma de São Paulo. In: SIMPÓSIO DE EXCELÊNCIA EM GESTÃO E TECONOLOGIA, 8., 2011, Resende. Anais... Resende.

SILVA, D. R.; BONACIM, C. A. G. A Influência da Lei de responsabilidade fiscal na gestão das contas públicas segundo a percepção de um contador. Sociedade, Contabilidade e Gestão, v. 5, n. 2, p.148-168, 2010.

SILVA FILHO, G. M.; PEREIRA, T. R. L.; DANTAS, M. G. S.; ARAÚJO, A. O. Análise da Eficiência nos Gastos Públicos com Educação Fundamental nos Colégios Militares do Exército em 2014. Revista Evidenciação Contábil \& Finanças, João Pessoa, v. 4, n. 1, p. 50-64, 2016.

SOUTO-MAIOR, J. Estratégias comunicativas para efetividade e sustentabilidade

Revista Brasileira de Desenvolvimento Regional, Blumenau, v. 1, n. 2, p. 141-155, 2013.

SPÍNDOLA, A. R. C.; LUIS NETTO, L. M.; SOUZA, V. B. A Gestão Social no Contexto da Gestão Ambiental: Análise da Criação e Operacionalização do Projeto 3R ARQUFSC. Revista de Gestão Social e Ambiental, São Paulo, v. 11, n. 1, p. 56-72, 2017. 
TRIBUNAL DE CONTAS DA UNIÃO-TCU. Portaria Segecex n n $^{\mathbf{3}}$ 31, de dezembro de 2010. Análise SWOT e Diagrama de Verificação de Risco Aplicados em Auditoria.

Acórdão do TCU n ${ }^{\circ} 1.752$, de 29 de junho de 2011. Estabelece uma integração de ações referente ao uso racional e sustentável de recursos naturais. Disponível em: $<$ https://jacoby.pro.br/novo/uploads/sustentabilidade/juris/eficientiza_o_energ_tica/tcu_ac_rd_o_n_ 1752_2011_plen_rio.pdf>. Acesso em: 07 jul. 2017.

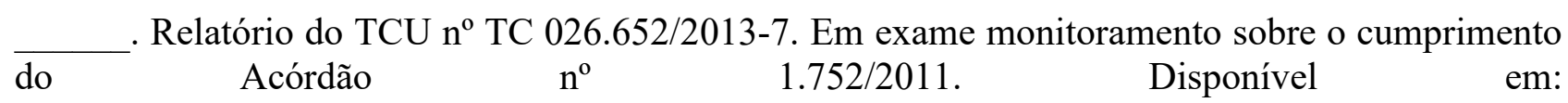
$<$ https://contas.tcu.gov.br/etcu/ObterDocumentoSisdoc?seAbrirDocNoBrowser=true\&codArqCatal ogado=7165581>. Acesso em: 01 jun. 2017.

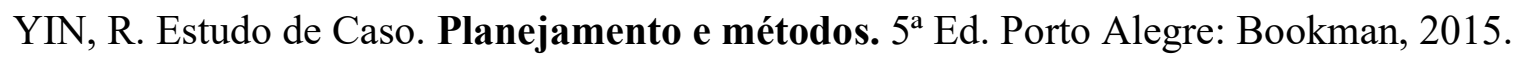

VASCONCELOS, C. C.; NOGUEIRA, R. A. Projeto Esplanada Sustentável: um caso de trajetória de múltiplos fluxos. In: CONGRESSO CONSAD DE GESTÃO PÚBLICA, 2., 2014, Brasília. Anais... Brasília.

VIEIRA, N. de A.; CASAGRANDE, M. L.; MARGON, D.; KAISER, C.; SANTOS, A. Mais com menos - Programa de controle e eficiência do Gasto Público do Governo do Estado do Espírito Santo. In: CONGRESSSO CONSAD DE GESTÃO PÚBLICA, 4., 2011, Brasília. Anais... Brasília.

\section{SOBRE OS AUTORES}

HUGO RAFAEL PEREIRA é mestrando em Ciências Contábeis na FAF/UERJ, pós graduado em Gestão Pública Municipal pela UFF e graduado em Administração de Empresas pelo CEFET/RJ. E-mail: hugo.rafael.adm@gmail.com

CÁTIA DE ASSIS SILVA DAS CHAGAS é mestranda em Ciências Contábeis na FAF/UERJ, pós graduada em Logística Empresarial pela UFF e graduada em Ciências Contábeis pela UNESA. E-mail: catiaachagas@gmail.com

GUILHERME TEIXEIRA PORTUGAL é doutor em Ciências da Engenharia/UFRJ, mestre em Ciências Contábeis/UFRJ, pós graduado em Finanças/PUC-Rio e graduado em Administração de Empresas/PUC-Rio. Professor Adjunto da FAF/UERJ lecionando no programa stricto senso em Ciências Contábeis, sendo atualmente o coordenador do curso.

E-mail: teixteix@hotmail.com

WALDIR JORGE LADEIRA SANTOS é doutor em Políticas Públicas e Formação Humana/ UERJ, pós graduado em Auditoria Interna/UNESA, em Administração de Recursos Humanos/ISEP, em Docência Superior/ISEP, graduado em Ciências Contábeis/ISESCB e graduado em Administração de Empresas/UNESA. Atualmente é presidente do Conselho Regional de Contabilidade do Estado do Rio de Janeiro e Professor Adjunto da FAF/UERJ lecionando no programa stricto senso em Ciências Contábeis.

E-mail:wcladeira@uol.com.br 


\section{Apêndice A - Roteiro de Entrevista com a equipe de trabalho do PES no IPEA}

\section{I- Informações Iniciais:}

Nome do Entrevistado:

Escolaridade:

Cargo/Função:

Tempo que trabalha no projeto:

\section{II- Perguntas sobre o PES}

1) Como ocorreu o processo de planejamento do PES no IPEA?

2) Como ocorreu o processo de implementação do PES no IPEA?

3) Como ocorreu o processo de escolha da equipe de trabalho do PES no IPEA?

4) O PES está conseguindo desenvolver as atividades previstas?

5) Quais os resultados do PES no IPEA?

6) O PES foi implementando conforme o planejado? Que mudanças ocorreram, e porquê?

7) Na sua opinião, o PES está dando certo? Se sim ou não, por quê?

8) Ocorreram melhorias no PES no IPEA? Se sim, quais foram?

\section{Apêndice B - Questionário de Pesquisa sobre PES no IPEA (Gestores do PES)}

\section{Termo de Consentimento Livre e Esclarecido}

Prezado(a) Senhor(a):

Você está sendo convidado(a) a responder as perguntas deste questionário de forma totalmente voluntária. Não existem respostas certas ou erradas. Trata-se apenas de um levantamento de opiniões. Antes de concordar em participar desta pesquisa e responder este questionário, é importante que você compreenda as informações e instruções contidas neste documento. O objetivo do estudo é avaliar as práticas sustentáveis de gestão e os objetivos previstos no PES que estão em operação no âmbito do Instituto de Pesquisa Econômica Aplicada (IPEA). Os respondentes não serão identificados em nenhum momento, mesmo quando os resultados desta pesquisa forem divulgados em qualquer forma. A participação na pesquisa consistirá apenas no preenchimento deste questionário, respondendo as perguntas sobre o perfil do respondente e sobre o PES.

Você concorda com o Termo? ( ) Sim ( ) Não

\section{Perfil dos respondentes}

1) Sexo ( ) Feminino ( ) Masculino

2) Escolaridade

( ) Nível médio ( ) Nível superior incompleto ( ) Nível Superior completo ( ) Pós-graduado

3) Há quanto tempo trabalha nesta Instituição?

( ) Até 1 ano ( ) De 1 a 5 anos ( ) De 5 a 10 anos ( ) Mais de 10 anos

\section{Processo de Implantação do PES}

4) A cultura dos colaboradores foi uma barreira para o processo de implementação?

( ) Discordo Totalmente 
( ) Discordo Parcialmente

( ) Não Concordo, Nem Discordo

( ) Concordo Parcialmente

( ) Concordo Totalmente

5) A mensuração dos recursos foi uma barreira para o processo de implementação?

( ) Discordo Totalmente

( ) Discordo Parcialmente

( ) Não Concordo, Nem Discordo

( ) Concordo Parcialmente

( ) Concordo Totalmente

6) Houve dificuldades na implantação do PES. Se sua resposta for sim, quais foram as dificuldades?

( ) Discordo Totalmente

( ) Discordo Parcialmente

( ) Não Concordo, Nem Discordo

( ) Concordo Parcialmente

( ) Concordo Totalmente

\section{Avaliação de metas e ações do PES}

7) Quais ações estão sendo realizadas para que as pessoas efetivamente assumam a propriedade do processo existente no PES? (Sustentabilidade)

8) As ações voltadas ao uso racional de recursos naturais, promovendo a sustentabilidade ambiental e socioeconômica estão sendo cumpridas quanto a: quantidade de pessoas beneficiadas, economia de recursos públicos, etc?

\section{Avaliação do Impacto do PES}

9) Quais foram as mudanças percebidas nos colaboradores em relação a utilização dos recursos naturais?

10) Como você avalia os resultados alcançados?

11) Que lições podem ser extraídas, que possam contribuir para aperfeiçoar a busca de resultados no PES?

\section{Gestão e Administrativa da sustentabilidade e eficiência}

12) Como o Órgão vem planejando e monitorando as ações adotadas e os seus resultados no PES?

13) Há sistematização no gerenciamento das ações de sustentabilidade e a institucionalização das mesmas?

14) Quais são os programas institucionais implantados pelo Órgão voltados ao uso racional de recursos naturais?

\section{Apêndice C - Questionário de Pesquisa sobre PES no IPEA (Servidores/Colaboradores)}

\section{Termo de Consentimento Livre e Esclarecido}

Prezado(a) Senhor(a):

Você está sendo convidado(a) a responder as perguntas deste questionário de forma totalmente voluntária. Não existem respostas certas ou erradas. Trata-se apenas de um levantamento de 
opiniões. Antes de concordar em participar desta pesquisa e responder este questionário, é importante que você compreenda as informações e instruções contidas neste documento. O objetivo do estudo é avaliar as práticas sustentáveis de gestão e os objetivos previstos no PES que estão em operação no âmbito do Instituto de Pesquisa Econômica Aplicada (IPEA).Os respondentes não serão identificados em nenhum momento, mesmo quando os resultados desta pesquisa forem divulgados em qualquer forma. A participação na pesquisa consistirá apenas no preenchimento deste questionário, respondendo as perguntas sobre o perfil do respondente e sobre o PES.

Você concorda com o Termo? ( ) Sim ( ) Não

\section{Perfil dos respondentes}

1) Sexo ( ) Feminino ( ) Masculino

2) Escolaridade

( ) Nível médio ( ) Nível superior incompleto ( ) Nível Superior completo ( ) Pós-graduado

3) Há quanto tempo trabalha nesta Instituição?

( ) Até 1 ano ( ) De 1 a 5 anos ( ) De 5 a 10 anos ( ) Mais de 10 anos

\section{Percepção dos respondentes para alguns aspectos relacionados ao PES}

4) A instituição estimula o consumo racional de energia elétrica? ( ) Sim ( ) Não

5) A instituição estimula o consumo racional de água? ( ) Sim ( ) Não

6) A instituição estimula o consumo racional de copo plástico e papel? ( ) Sim ( ) Não

7) A instituição estimula a conservação dos bens imóveis? ( ) Sim ( ) Não

A próxima questão poderá ser respondida com mais de uma opção.

8) Qual a forma utilizada pela Instituição para estimular a economia dos recursos?

( ) Palestras

( ) Cartazes

( ) Benefícios

( ) Comunicações internas

( ) Metas departamentais 